\title{
Evaluation of an Absorbable Collagen Membrane in Treating Class II Furcation Defects
}

\author{
Hom-Lay Wang, ${ }^{*}$ Robert B. O’Neal, ${ }^{*}$ Clifford L. Thomas,${ }^{\dagger} Y u$ Shyr,${ }^{\ddagger}$ and \\ R. Lamont MacNeil*
}

RECENT RESEARCH HAS FOCUSED upon the utilization of an absorbable collagen membrane in guided tissue regeneration (GTR). Concern exists as to whether this type of membrane is beneficial in the treatment of periodontal defects. The purpose of this study was to evaluate the effect of a type I bovine collagen membrane on treatment of Class II furcation defects. Twelve systemically healthy patients (six male and six female, ages 32 to 68 ) were treated. Each had bilateral mandibular furcation defects with attachment loss $\geq 6 \mathrm{~mm}$. Prior to surgery all patients completed initial therapy including scaling and root planing. At the time of the surgery, teeth were randomly assigned to either a control (flap debridement alone) or test (flap debridement plus collagen membrane) group. Data were collected on the day of surgery, and 2, 4, and 6 months post-surgery and at the 12 month re-entry surgery. Clinical measurements included probing depth (PD), clinical attachment level (CAL), gingival recession (GR), stent to base of defect (SB), crestal bone to base of defect (CB), width of defect, and mobility. Statistical analysis was performed utilizing the paired $t$ test. Both control and test groups demonstrated significant $(P<0.05)$ improvement at 12 months re-entry in PD, CAL, SB, and CB when compared to the presurgery status. While there is no significant difference in PD, CAL, GR, width of defect, and mobility between control and test groups, sites treated with the collagen membrane had significantly higher bone fill (SB and CB) at re-entry. A significant improvement of furcation horizontal bone repair and defect improvement was noted in the collagen membranes-treated sites as compared to the presurgery status. No foreign body reaction was observed in either group during this study. This study suggests that the use of absorbable collagen membrane may have beneficial effects in the treatment of Class II furcal defects. J Periodontol 1994; 65:1029-1036.

Key Words: Collagen therapeutic use; furcation therapy; guided tissue regeneration; membranes, barrier; randomized clinical trial.

Guided tissue regeneration (i.e., epithelial exclusion and selective repopulation of the root surface by multipotential cells) utilizing non-resorbable occlusive membranes has become an accepted mode of therapy in periodontics. ${ }^{1-2} \mathrm{Al}-$ though proven efficacious in promoting new connective tissue attachment, non-resorbable membranes are not without their shortcomings. For example, recession with bacterial contamination is a common clinical finding. ${ }^{3}$ In addition, the need for a second surgical procedure to retrieve the membrane may also disrupt healing. We have been conducting research on an absorbable barrier composed of type

*Department of Periodontics/Prevention/Geriatrics, School of Dentistry, University of Michigan, Ann Arbor, MI.

${ }^{+}$Private practice, Cleveland, $\mathrm{OH}$.

'Department of Biostatistics, School of Public Health, University of Michigan, Ann Arbor, MI.
I collagen. Collagen has a number of properties which make it practical for use as a barrier. ${ }^{4-7}$

Collagen is the most abundant protein in the body and the main constituent of periodontal connective tissue. It comprises approximately $30 \%$ of the human body and functions as the extracellular framework for all multi-cellular animals. The rationale for using collagen as a barrier is based on the following: First, collagen possesses hemostatic properties. ${ }^{8}$ Wikesjö et al. have indicated that in order for regeneration to occur, the developing clot must form and adhere to the root surface thereby facilitating proper wound maturation. ${ }^{9}$ Because collagen is a hemostatic agent by virtue of its ability to aggregate platelets, it may further facilitate wound maturation by enhancing the initial blood clot and fibrin linkage formation. This concept is supported by Haney et al. who indicated that clot stabilization, wound 
stability, space provision, epithelial cell exclusion, and complete gingival coverage are critical factors for the success of the GTR procedure. ${ }^{10}$ Second, a collagen membrane, once infiltrated by vascular channels, may serve as a lattice for migrating periodontal ligament fibroblasts." ${ }^{11}$ Third, collagen has been found to be chemotactic for fibroblasts in vitro, ${ }^{12}$ a property that may enhance cell migration into the space formed between the root surface and the collagen membrane. Clinical trials and animal studies have shown most collagen membranes to be effective in inhibiting epithelial migration and promoting new connective tissue attachment. ${ }^{13-14}$ Fourth, collagen can be formed into many shapes and can easily be manipulated and adapted to the root surface. Fifth, collagen is a weak immunogen. ${ }^{15}$ Sixth, collagen is a cross-linked material which is bioabsorbable, eliminating the need for re-entry surgery to remove it. ${ }^{16}$ In total, these properties suggest that collagen may have applications as a barrier material for use in regeneration therapy. Thus, the following study was designed to evaluate the effect of a type I bovine collagen membrane in treatment of Class II furcation defects.

\section{MATERIALS AND METHODS}

\section{Patients}

The research protocol herein described was approved by the Human Subjects Review Committee at the School of Dentistry, The University of Michigan. Twelve systemically healthy patients (ages 32 to 68), six males and six females, were included in the study. The following criteria were used to select the patients for this clinical study: 1) evidence of advanced periodontitis; 2) bilateral Class II mandibular furcation defects exhibiting attachment loss $\geq 6$ $\mathrm{mm} ; 3)$ radiographic evidence of a Class II mandibular molar defect; 4) excellent systemic health; 5) no antibiotic therapy in the past 6 months; and 7) no periodontal surgery in the past 12 months. Informed consent from all subjects who met the criteria and agreed to participate in the study were obtained. Patients entered the study either directly after a standard preparation stage (i.e., oral hygiene instruction, scaling and root planing, and other initial disease control procedures) or upon the decision that surgical intervention was needed during maintenance therapy.

\section{Measurements}

Clinical data including probing depths (PD) of the periodontal defects, gingival recession (GR), mobility and plaque (PI) and gingival (GI) indices were collected at baseline (one week prior to the surgery) and 2, 4 and 6 months post surgery. PD were obtained using a North Carolina $15 \mathrm{~mm}$ probe: the deepest point at six sites of selected teeth was recorded. GR was measured from the cementoenamel junction (CEJ) to the free gingival margin. Tooth mobility was detected utilizing Miller's classification $(0=$ no mobility; 1 = the first distinguishable sign of movement greater than normal; $2=$ movement of $1 \mathrm{~mm}$ from normal position in any direction; and $3=$ movement of more than $1 \mathrm{~mm}$ in any direction). ${ }^{17} \mathrm{PI}$ was recorded according to Silness and Löe. ${ }^{18}$ GI was measured using the criteria described by Löe and Silness. ${ }^{19}$ Additional clinical measurements were performed at the time of periodontal surgery and at one year re-entry surgery. Clinical attachment levels (CAL) were measured using a pre-fabricated acrylic stent and a North Carolina $15 \mathrm{~mm}$ probe; the stent was grooved at the time of surgery to record the orientation of the probe. When placed in the osseous defect, an occlusal ledge served as an occlusal landmark. The following measurements were made: SB, stent to the base of defect, stent to the free gingival margin; $\mathrm{CB}$, crest of bone to base of defect; and buccolingual/mesiodistal morphology of the furcation defects (Fig. 1).

\section{Surgical Protocol}

All surgical procedures were performed by the same periodontist. Bilateral mandibular furcation defects were randomly assigned by coin toss to receive either flap debridement plus collagen membrane (test) or flap debridement alone (control) before the defects were debrided. The surgical procedure involved the elevation of a full thickness mucoperiosteal flap with intracrevicular incisions, preserving as much keratinized tissue as possible. The furcation defects were debrided and all root surfaces were completely scaled and root planed by hand, ultrasonic, and rotating instrumentation. The test material was a collagen mem-

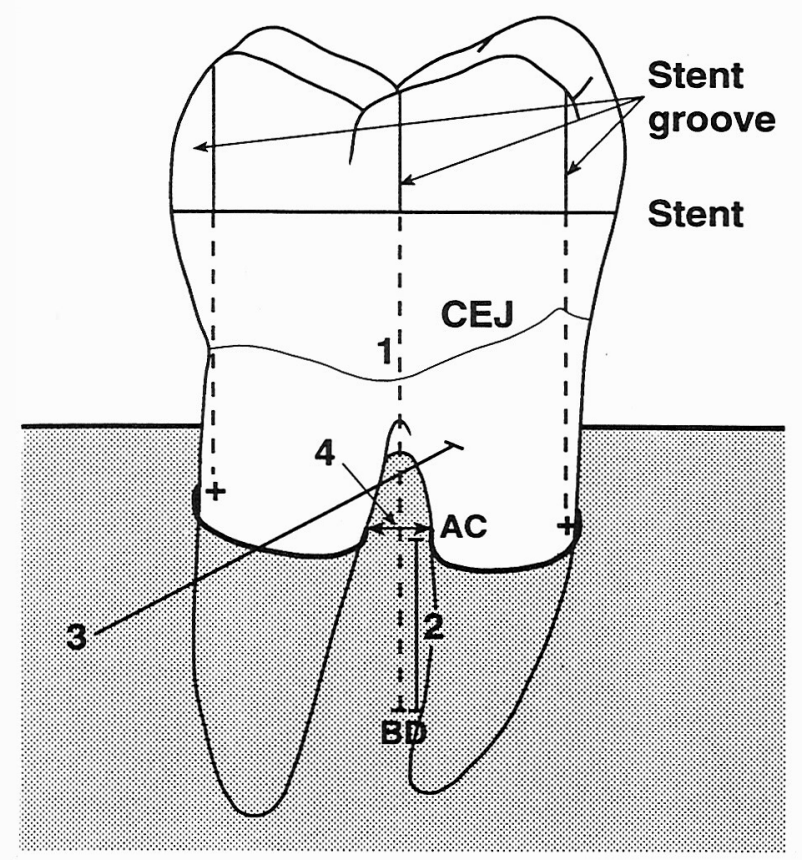

Figure 1. Method used to analyze the furcation defect. (1) occlusal surface of stent to a line drawn from the mesial to distal at the base of the defect $(B D) ;(2)$ crest of bone $(A C)$ to base of the defect (BD); (3) horizontal probing depth (horizontal $P D$ ) from a line tangential to the root surface to the horizontal extent of the defect; (4) vertical probing depth (vertical $P D)$ measures the line from the mesial to the distal at the bottom of the furcation defect (modified from Paul, et al. ${ }^{23}$ ). 
Table 1. Clinical Parameters Comparison Between Collagen Treated and Flap Debridement Control

Sites (mean \pm standard error) at Different Time Periods ( $n=12$ per group)

\begin{tabular}{llccccc}
\hline $\begin{array}{l}\text { Clinical } \\
\text { Parameters }\end{array}$ & Groups & Baseline & 2 Months & 4 Months & 6 Months & 12 Months \\
\hline Gingival & Collagen & $0.92 \pm 0.15$ & $0.42 \pm 0.15$ & $0.42 \pm 0.15$ & $0.50 \pm 0.19$ & $0.42 \pm 0.15$ \\
index & Control & $0.83 \pm 0.17$ & $0.42 \pm 0.15$ & $0.42 \pm 0.15$ & $0.50 \pm 0.19$ & $0.42 \pm 0.15$ \\
Plaque & Collagen & $1.00 \pm 0.17$ & $0.33 \pm 0.14$ & $0.17 \pm 0.11$ & $0.50 \pm 0.19$ & $0.33 \pm 0.14$ \\
index & Control & $0.67 \pm 0.14$ & $0.50 \pm 0.15$ & $0.33 \pm 0.14$ & $0.50 \pm 0.15$ & $0.50 \pm 0.15$ \\
Probing & Collagen & $5.33 \pm 0.26$ & $3.74 \pm 0.17$ & $3.74 \pm 0.19$ & $3.81 \pm 0.23$ & $4.01 \pm 0.25$ \\
depths & Control & $5.48 \pm 0.29$ & $4.07 \pm 0.18$ & $3.88 \pm 0.19$ & $4.04 \pm 0.20$ & $4.61 \pm 0.47$ \\
\hline
\end{tabular}

Table 2. Clinical Measurements ( $\mathrm{mm}$ ) for Collagen and Flap Debridement Control Sites at Baseline ( $n=12$ per group)

\begin{tabular}{lrrr}
\hline Measurement & $\begin{array}{c}\text { Collagen Sites } \\
(\text { mean } \pm \text { SE) }\end{array}$ & $\begin{array}{r}\text { Control Sites } \\
\text { (mean } \pm \text { SE) }\end{array}$ & \multicolumn{1}{c}{ Difference } \\
\hline Probing depths & $6.92 \pm 0.79$ & $6.92 \pm 2.43$ & $0.00 \pm 0.41$ \\
Attachment level & $12.08 \pm 2.43$ & $11.58 \pm 2.43$ & $0.50 \pm 1.31$ \\
$\begin{array}{l}\text { Stent to free gingival } \\
\quad \text { margin }\end{array}$ & $5.58 \pm 1.31$ & $5.25 \pm 1.60$ & $0.33 \pm 0.35$ \\
$\begin{array}{l}\text { Stent to base of defect } \\
\text { Crest bone to base of }\end{array}$ & $13.42 \pm 2.63$ & $13.75 \pm 2.63$ & $-0.33 \pm 0.62$ \\
$\quad$ defect & & & \\
$\begin{array}{l}\text { Furcation measurements } \\
\quad \text { Buccolingual width }\end{array}$ & $6.17 \pm 1.70$ & $4.17 \pm 2.25$ & $0.00 \pm 0.52$ \\
$\quad \begin{array}{l}\text { Mesiodistal width } \\
\text { Area of defects }\end{array}$ & $3.08 \pm 2.66$ & $5.58 \pm 2.67$ & $0.42 \pm 0.38$ \\
\hline
\end{tabular}

No statistically-significant difference $=P<0.05$.

brane ${ }^{\S}$ prepared from purified bovine Achilles tendon in a chemically cross-linked form and supplied in individual 18 $\mathrm{mm} \times 38 \mathrm{~mm} \times 0.15-0.22 \mathrm{~mm}$ sterile pieces. The material was individually cut to proper dimension and then placed over the defect extending $2 \mathrm{~mm}$ beyond the edge of the furcation defect. The membrane was not sutured unless the size of the defect necessitated such procedures. Any suturing of the membrane was accomplished with 5-0 chromic gut sutures. The flap was subsequently sutured securely to its original position with 4-0 black silk sutures, with care to ensure that no portion of the membrane was left exposed on the day of surgery. On the control side all surgical procedures were identical, except that no membrane was placed. All patients received routine written and oral postoperative instructions and were prescribed doxycycline 100 $\mathrm{mg} / \mathrm{day}$ for 2 weeks. Each patient was instructed to rinse with $0.12 \%$ chlorhexidine gluconate for a period of 6 weeks. Sutures were removed 7 to 10 days after the surgery and any change in position of the membrane noted. Patients returned weekly for 4 weeks for observation of any adverse tissue reactions. Patients were then seen at 2, 4, and 6 months post-surgery for GI, PI, PD, and GR recording; tissue evaluation; plaque debridement; and oral hygiene review.

\section{One Year Re-Entry Surgery}

At the end of 12 months, the patients were scheduled for re-entry surgery. Clinical measurements (GI, PI, PD, CAL,

${ }^{\S}$ BioMend (formerly Periobarrier), Calcitek Inc., Carlsbad, CA.

uperidex, Procter \& Gamble, Cincinnati, $\mathrm{OH}$. stent to the free gingival margin, SB, CB, and mobility) of the involved tooth were recorded prior to the surgery. Surgical re-entry consisted of sulcular incisions to preserve attached gingiva and interdental papillae. Full-thickness mucoperiosteal flaps were designed to expose the previously treated furcation areas for clinical photographs and measurements as previously described. Flaps were then replaced and sutured. Patients were seen at one week post-surgery for suture removal, and then placed on a closely supervised 3-month schedule for supportive periodontal treatment.

\section{Statistical Analysis}

The data were organized, presented as means \pm standard error and analyzed using the SAS system. Repeated measures analysis of variance (ANOVA) was used to evaluate changes in clinical parameters within groups at different times. The paired $t$-test was utilized to compare the clinical measurements between control and test groups at each time period. Significance was reported at the $\alpha=0.05$ level.

\section{RESULTS}

Twelve patients (mean age $46.42 \pm 9.15$ ) with bilateral similar furcation defects were studied. During the course of this study, no adverse tissue reaction, infections, or delayed healing were reported. As shown in Table 1, GI and PI decreased dramatically in both test and control sites at two months post-surgery. This noticeable downward shift was maintained throughout the experimental (12 month) period. The mean PD was reduced significantly at $2,4,6$, and 12 months post-surgery when compared to baseline in both groups. No significant differences of GI, PI, and mean PD were noted between the test and control sites at any time point.

Only mid-buccal or -lingual furca measurements from stent to free gingival margin, SB, and CB were used for statistical analysis. No differences were noted at baseline between collagen treated sites and flap debridement control sites for any clinical parameters (Table 2). Table 3 presents a comparison of clinical measurements for test and control sites at one year re-entry. A statistically significant variance was observed in CB (crestal bone to base of defect) for test (collagen) site when compared to control site at one year re-entry. Other parameters, while showing positive trends and differences, did not demonstrate statistically significant changes. 
Table 3. Clinical Measurements (mm) for Collagen and Flap Debridement Control Sites at One Year Re-Entry $(n=12$ per group)

\begin{tabular}{lcrr}
\hline Measurements & $\begin{array}{c}\text { Collagen Sites } \\
\text { (mean } \pm \text { SE) }\end{array}$ & $\begin{array}{r}\text { Control Sites } \\
\text { (mean } \pm \text { SE) }\end{array}$ & \multicolumn{1}{c}{ Difference } \\
\hline Probing depths & $4.08 \pm 1.50$ & $5.00 \pm 3.05$ & $-0.92 \pm 0.61$ \\
Attachment level & $10.42 \pm 2.07$ & $10.92 \pm 2.71$ & $-0.50 \pm 0.80$ \\
$\begin{array}{l}\text { Stent to free gingival } \\
\quad \text { margin }\end{array}$ & $6.42 \pm 1.62$ & $6.33 \pm 1.92$ & $0.08 \pm 0.48$ \\
$\begin{array}{l}\text { Stent to base of defect } \\
\text { Crest bone to base of }\end{array}$ & $10.92 \pm 1.88$ & $12.25 \pm 2.73$ & $-1.33 \pm 0.65$ \\
$\quad$ defect & $1.33 \pm 1.07$ & $2.67 \pm 2.33$ & $-1.33 \pm 0.43^{*}$ \\
$\begin{array}{l}\text { Furcation measurements } \\
\quad \text { Buccolingual width }\end{array}$ & $3.96 \pm 2.99$ & $4.50 \pm 3.45$ & $-0.54 \pm 0.64$ \\
$\quad \begin{array}{l}\text { Mesiodistal width } \\
\text { Area of defects }\end{array}$ & $2.71 \pm 0.94$ & $3.08 \pm 0.87$ & $-0.38 \pm 0.23$ \\
\hline
\end{tabular}

${ }^{*}$ Statistically significant difference $=P<0.05$

Table 4. Clinical Changes in Class II Furcation Invasions (mm) One Year After Treatment With and Without Collagen Barrier Placement $(\mathrm{n}=12$ per group)

\begin{tabular}{lccc}
\hline Measurements & $\begin{array}{c}\text { Collagen Sites } \\
\text { (mean } \pm \text { SE) }\end{array}$ & $\begin{array}{c}\text { Control Sites } \\
\text { (mean } \pm \text { SE) }\end{array}$ & Difference \\
\hline Probing depths & $2.84 \pm 0.41^{*}$ & $1.92 \pm 0.67^{*}$ & $0.92 \pm 0.61$ \\
Attachment level & $1.67 \pm 0.22^{*}$ & $0.67 \pm 0.62$ & $1.00 \pm 0.65$ \\
$\begin{array}{l}\text { Stent to free gingival } \\
\quad \text { margin }\end{array}$ & $-0.83 \pm 0.29^{*}$ & $-1.08 \pm 0.36^{*}$ & $0.25 \pm 0.33$ \\
$\begin{array}{l}\text { Stent to base of defect } \\
\text { Crest bone to base of } \\
\quad \text { defect }\end{array}$ & $2.50 \pm 0.38^{*}$ & $1.50 \pm 0.26^{*}$ & $1.00 \pm 0.41^{+}$ \\
$\begin{array}{l}\text { Furcation measurements } \\
\quad \text { Buccolingual width }\end{array}$ & $2.83 \pm 0.41^{*}$ & $1.50 \pm 0.26^{*}$ & $1.33 \pm 0.47^{+}$ \\
$\quad \begin{array}{l}\text { Mesiodistal width } \\
\text { Area of defects }\end{array}$ & $0.38 \pm 0.23 *$ & $1.08 \pm 0.61$ & $0.96 \pm 0.56$ \\
\hline
\end{tabular}

*Statistically significant between baseline and one year reentry at $P$ $<0.05$.

${ }^{\dagger}$ Statistically significant difference $=P<0.05$.

When the one year re-entry values were compared to the baseline measurements, both treatment modalities showed significant reduction $(P<0.05)$ in all clinical parameters from baseline (Table 4). The mean probing depth improvement for the collagen barrier-treated defects was $2.84 \mathrm{~mm}$ as compared to $1.92 \mathrm{~mm}$ for the controls. Collagen-treated sites showed statistically significant gain of attachment $(1.67 \mathrm{~mm})$, whereas there was no significant gain for the controls $(0.67 \mathrm{~mm})$. No difference was noted between test and control sites with regard to gingival recession. The collagen barrier sites showed an improvement in defect fill (stent to base of defect) $(2.50 \mathrm{~mm}$ vs. $1.50 \mathrm{~mm})$ and vertical bone fill (crest of bone to base of defect) ( $2.83 \mathrm{~mm}$ vs. 1.50 $\mathrm{mm}$ ) which was statistically significant in comparison to the control sites. When considering the furcation measurements, the sites treated with collagen membrane showed a significant improvement in horizontal probing depths and defect improvement as compared to the baseline. Defect area improvement was calculated from this formula: defect area improvement $=\left(1 / 2 \times\right.$ Horizontal $^{\text {initial }} \times$ Vertical $\left.^{\text {intialal }}\right)$ - $\left(1 / 2 \times\right.$ Horizontal $^{\text {re-entry }} \times$ Vertical $\left.^{\text {rc-entry }}\right)$. No significant
Table 5. Percentage Reduction in Vertical Bone Fill and Horizontal Furcation Measurement After One Year $(n=12)$

Clinical

\begin{tabular}{clllll} 
parameters & Groups & \multicolumn{1}{c}{ None } & \multicolumn{1}{c}{$0-25 \%$} & \multicolumn{1}{c}{$26-50 \%$} & $>50 \%$ \\
\hline Vertical & Collagen & $0(0 \%)$ & $0(0 \%)$ & $2(16.7 \%)$ & $10(83.3 \%)$ \\
bone fill & Control & $0(0 \%)$ & $4(33.3 \%)$ & $3(25 \%)$ & $5(41.7 \%)$ \\
Horizontal & Collagen & $0(0 \%)$ & $2(16.7 \%)$ & $6(50 \%)$ & $4(33.3 \%)$ \\
bone fill & Control & $1(8.3 \%)$ & $6(50 \%)$ & $2(16.7 \%)$ & $3(25 \%)$
\end{tabular}

improvement was noted on the control treated sites when compared to the pre-surgery measurements.

At re-entry, the percent of improvement in vertical bone fill and furcation horizontal (bucco-lingual width) probing depth was calculated for each treatment site. The data were grouped in $25 \%$ increments (Table 5). The collagen sites had 10 of the 12 sites with vertical bone fill greater than $50 \%$ as compared to 5 out of 12 in the control groups. Ten furcations treated with collagen membrane showed a reduction in the horizontal probing depth greater than $25 \%$, while less than half (5) of the controls demonstrated the same.

No adverse gingival tissue reactions were observed. In addition, at no time was displacement of the collagen membrane noted. None of the treated teeth had a change in mobility at one year and no significant differences were noted between groups. Surgical procedures and treatment results are illustrated in Figures 2 and 3.

\section{DISCUSSION}

The use of collagen as a barrier to enhance cell/tissue regeneration to a previously diseased root has gained considerable attention recently. ${ }^{4-7}$ Here we describe the use of a bioabsorbable type I collagen membrane derived from bovine tendon. This membrane is biodegradable and its absorption rate is controlled by its degree of crosslinking, with an average retention time of 6 to 7 weeks. ${ }^{20}$ The membrane is semipermeable with a pore size of $0.004 \mu \mathrm{m}$ and can prevent epithelial cell penetration while permitting passage of nutrients. This study was designed to evaluate the barrier in treating Class II mandibular molar furcation defects in humans. The results of this one year re-entry clinical trial indicate that the placement of type I bovine collagen in Class II furcations results in significantly greater defect fill $(2.50 \mathrm{~mm}$ vs. $1.50 \mathrm{~mm})$ and vertical bone fill $(2.83 \mathrm{~mm}$ vs. $1.50 \mathrm{~mm}$ ) when compared to control sites. Similar results were reported by Blumenthal, ${ }^{21}$ who showed that sites treated with a different collagen membrane gained vertical open probing new attachment at 12 months re-entry when compared to baseline. Our results are also in agreement with the 3 months re-entry study by Van Swol et al., ${ }^{6}$ who reported that collagen treated sites had significantly higher vertical bone fill (from CEJ to base of the bony defect) when compared to the control groups. Similar findings were also reported by Chung et al. ${ }^{7}$ in their one year study.

When both treatment modalities (with and without col- 

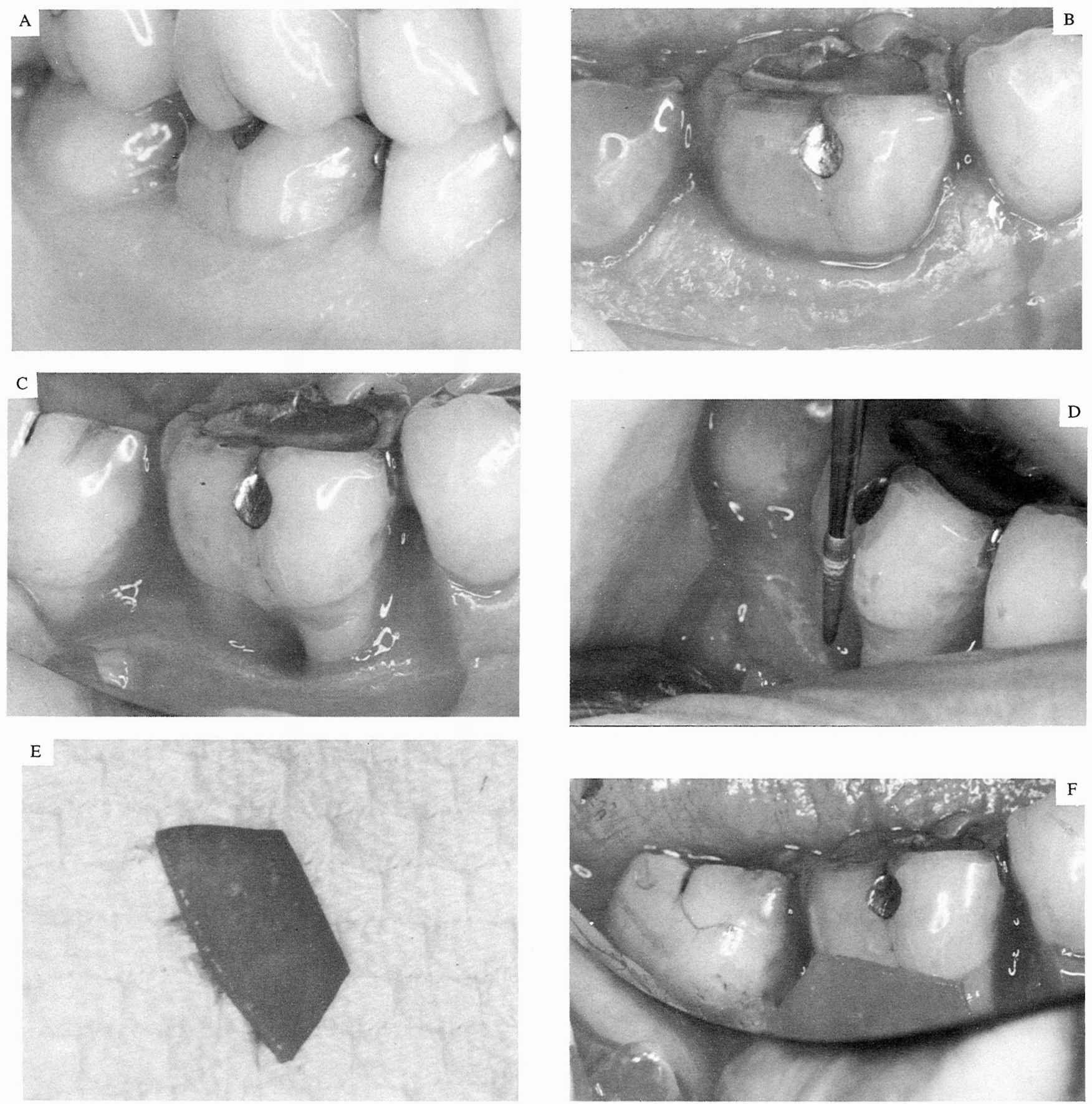

Figure 2. Demonstration of clinical placement of collagen membrane in a molar tooth (\#30) with Class II furcation involvement. A. pre-surgery; B. buccal initial incision designed to preserve papillary tissue with a vertical releasing incision on the mesial; C. surgical exposure of a class II furcation defect with evidence of cervical enamel projection; D. low speed diamond bur to remove the cervical enamel projection; E. membrane trimmed; F. membrane placed without suture.

lagen barrier) were compared, both showed significant improvement in clinical measurements from baseline (Table 4). The mean probing depth improvement and attachment gain for the collagen barrier treated defects was $2.84 \mathrm{~mm}$ and $1.67 \mathrm{~mm}$, respectively, as compared to $1.92 \mathrm{~mm}$ and $0.67 \mathrm{~mm}$ for the control sites. Although collagen-treated sites tended to respond more favorably, surgical intervention either with or without membrane placement resulted in reducing probing depth at furcal sites. Similar results have been reported by Paul et al. ${ }^{22}$

The positive effect of collagen membrane treatment on furcation sites was most evident in improvement in horizontal probing depth and defect fill. The sites treated with collagen membrane showed a significant improvement in horizontal bone repair $(2.04 \pm 0.43 \mathrm{~mm})$ and defect improvement $(3.90 \pm 0.88 \mathrm{~mm})$ compared to baseline. How- 

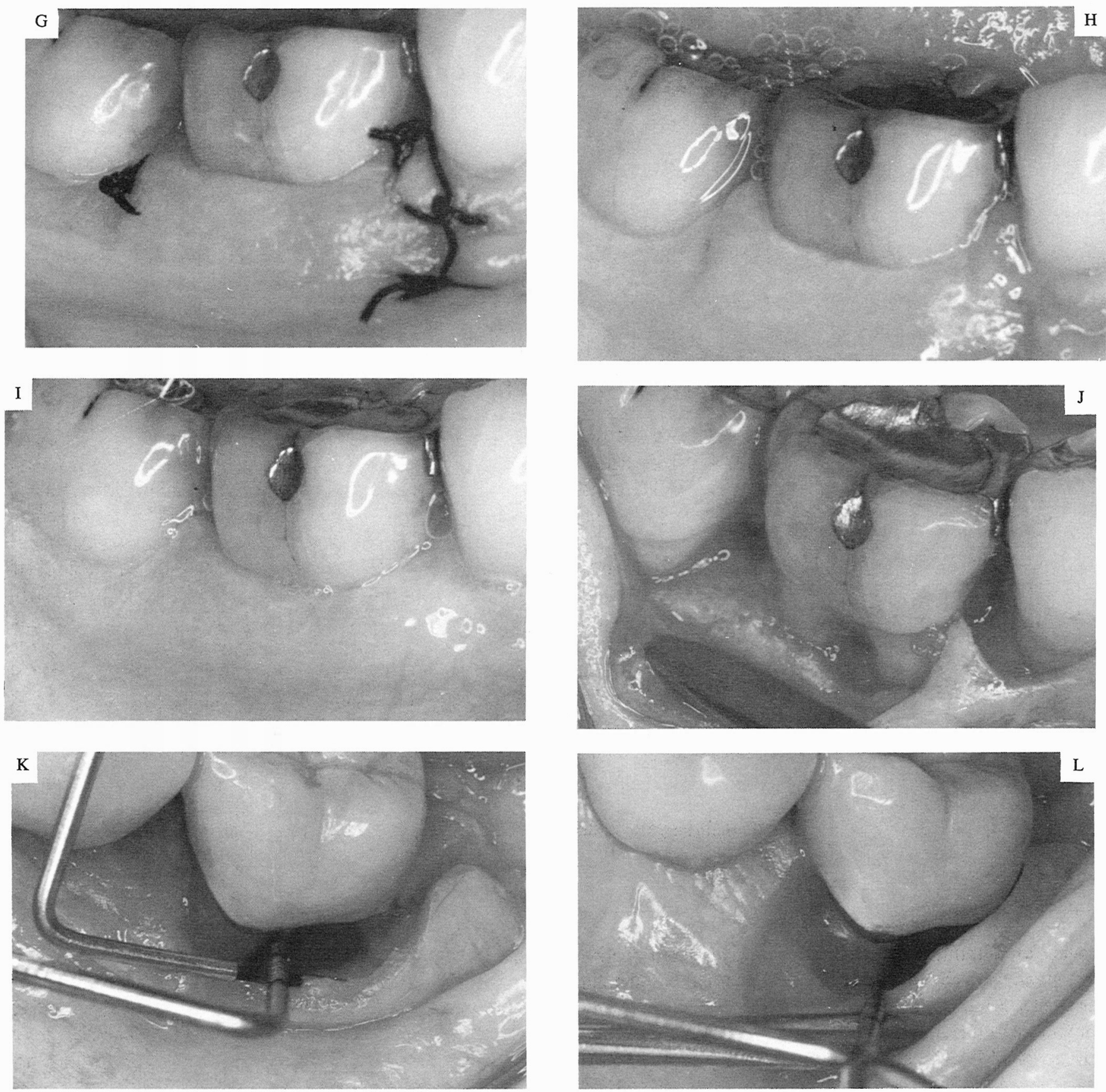

Figure 2. (Continued) G. tissues sutured; H. one-week post-surgery healing; I. one-year post surgery healing; J. one-year re-entry showed newly formed tissue; K. surgical exposure of the flap debridement treated control site; $\mathbf{L}$. one year re-entry of the flap debridement treated control site indicated no gain of the newly formed tissue.

ever, no significant improvement was noted on the control treated sites $(1.08 \pm 0.61 \mathrm{~mm}$ and $2.07 \pm 1.48 \mathrm{~mm}$ respectively) compared to the baseline. This finding is in agreement with Anderson, ${ }^{23}$ who reported that collagen barrier treated sites had $87 \%$ of "approximate defect area" resolution in furcation areas compared to $49 \%$ restoration in the flap debridement control sites. In addition, several studies have reported on these criteria with use of expanded polytetrafluoroethylene (ePTFE). Lekovic et al. ${ }^{24}$ showed only
$0.12 \mathrm{~mm}$ horizontal fill at 6 month re-entry and Caffesse et al. ${ }^{25}$ reported $1.4 \mathrm{~mm}$ gain. This comparison indirectly suggests that collagen membrane may have better potential to regenerate horizontal bone fill than the ePTFE non-absorbable membrane.

The major benefit of using a bioabsorbable collagen membrane instead of ePTFE barriers is that collagen is a natural protein of the human body which is degraded by host enzymes, hence eliminating the need for a second re- 

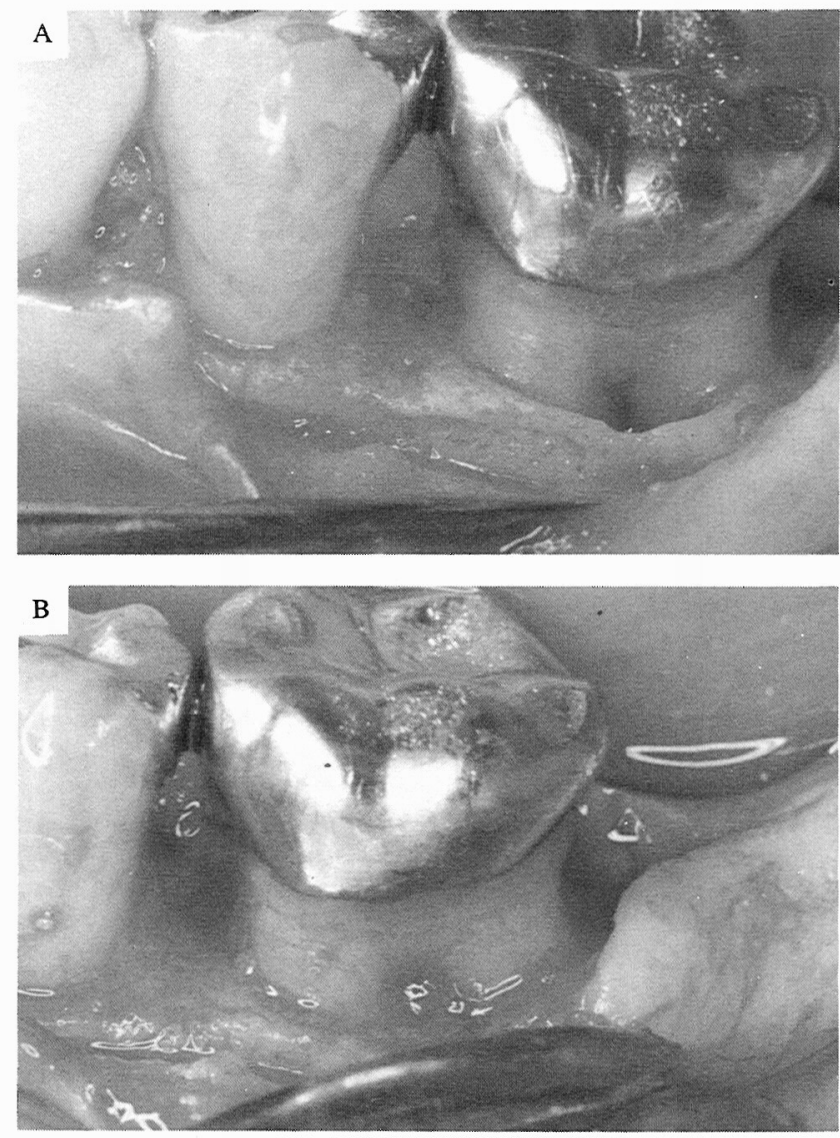

Figure 3. Results of collagen membrane treatment. A. surgical exposure of class II furcation defect with $5 \mathrm{~mm}$ vertical probing depth from the alveolar crest and $5 \mathrm{~mm}$ of horizontal probing component; B. one-year re-entry showing furcation filled with attached, dense, non-probeable tissue as seen in e-PTFE treated cases.

trieval surgery. Thus, the possibility of losing attachment gained through a GTR procedure by secondary surgery is reduced..$^{26}$ Also, animal studies by Pitaru et al..$^{5}$ and Pfieffer et al. ${ }^{4}$ demonstrated that collagen membranes can prevent apical migration of epithelium and enhance new connective tissue attachment during periodontal wound healing to the same extent as ePTFE membranes. ${ }^{1}$ Although, statistically significant gains in clinical attachment levels were not observed in this present study, positive clinical trends were observed for collagen membrane-treated sites. This observation agrees with a recent study by Blumenthal ${ }^{21}$ which reported that both collagen membrane and ePTFE are effective in gaining vertical open probing new attachment and horizontal open and closed probing new attachment. In addition, it was also reported that sites treated with collagen membrane had less membrane exposure when compared to ePTFE treated sites; ${ }^{21}$ we report similar findings in this study. Lack of membrane exposure may be explained by the fact that collagen is chemotactic for fibroblasts ${ }^{12}$ which may enhance initial flap stabilization and the potential for regeneration. This property may reduce the detrimental effects which we believed to accompany exposure of mem- brane during GTR procedure and microbial colonization of barrier materials following GTR therapy.,27

Adverse tissue reaction, infections, or delayed healing were not observed following surgical placement of a bioabsorbable collagen barrier in this study. The presence of the collagen membrane did not increase plaque accumulation or gingival inflammation (Table 1), even though a mild host inflammatory response accompanied absorption of the membrane. A previous study has demonstrated that the presence of collagen membrane was not associated with increased bacterial colonization and did not alter the local microflora when compared to the flap debridement and untreated control sites. ${ }^{28}$ These findings are in agreement with Blumenthal ${ }^{21}$ and are further supported by Choi et al., ${ }^{29}$ who reported that collagen matrix placed in a canine fenestration wound neither enhances nor inhibits periodontal healing. Also, Stein et al. showed that there were no adverse effects on the adjacent healthy sites when a collagen membrane was placed during GTR procedures. ${ }^{30}$ Kamer and Churukian reported that $2 \%$ of patients receiving injectable collagen experienced localized hypersensitivity reactions at the site of injection..$^{31}$ No such reaction was noted in patients in this study. Johns et al. indicated that collagen membrane placed during GTR procedures does not elicit an antibody reaction. ${ }^{32}$ The low antigenicity of this product is likely related to the fact that the collagen membrane is treated with pepsin to remove its tyrosine (the most highly antigenic portion) content. Therefore, the product appears to be a biocompatible and safe material. The collagen barrier used in this study is easy to trim, adapt, and secure to the defect. When compared to ePTFE membrane, the collagentreated sites tend to show better tissue response during early wound healing. ${ }^{21}$ Since collagen is a hemostatic agent by virtue of its ability to aggregate platelets, it may further facilitate wound maturation by enhancing the initial blood clot and fibrin linkage formation. ${ }^{8}$ This concept is supported by Haney et al. who indicated that clot stabilization, wound stability, space provision, epithelial cell exclusion, and complete gingival coverage are critical factors for the success of GTR procedures. ${ }^{10}$

A limitation of this study is the small sample size used; this shortcoming may have some affect or influence the power and significance of statistical tests used in this study. Future studies should include a larger sample size and longer follow-up time to determine the long-term effect of collagen membrane treatment. Within the scope of this initial study, the following conclusions can be drawn: 1) the placement of type I bovine collagen membrane during surgery on Class II furcations results in significantly higher defect fill and vertical bone fill when compared to the control sites; 2) sites treated with collagen membranes show a significant improvement in horizontal bone repair and defect improvement when compared to the presurgical status; 3) the collagen membrane-treated sites are twice as likely to have greater than $50 \%$ vertical bone fill than the control sites; 4) no significant differences were observed in attachment gain 
probing depth reduction, or mobility; 5) the collagen membrane is well tolerated by the tissues with test and control sites exhibiting comparable recession pattern, in general tissue healing was similar to that observed following conventional flap therapy; and 6) surgical treatment with or without a collagen membrane showed significant improvement in clinical parameters from baseline.

\section{Acknowledgments}

The authors thank Dr. Frederic Smith for his assistance in the preparation of this manuscript. This study was supported, in part, by Colla-Tec (now Integra Life Sciences) Corporation, Princeton, NJ.

\section{REFERENCES}

1. Gottlow J, Nyman S, Karring T, et al. New attachment formation as the result of controlled tissue regeneration. J Clin Periodontol 1984; 11:494-503.

2. Pontoriero R, Lindhe J, Nyman $\mathrm{S}$, et al. Guided tissue regeneration in degree II furcation-involved mandibular molars. A clinical study. J Clin Periodontol 1988; 15:247-254.

3. Selvig KA, Kersten BG, Chamberlain ADH, Wikesjö UME, Nilveus RE. Regenerative surgery of intrabony periodontal defects using ePTFE barrier membranes: Scanning electron microscopic evaluation of retrieved membranes versus clinical healing. $J$ Periodontol 1992; 63:974-978

4. Pfeifer J, Van Swol RL, Ellinger R. Epithelial exclusion and tissue regeneration using a collagen membrane barrier in chronic periodontal defects: A histologic study. Int J Periodontics Restorative Dent 1989; 9:262-273.

5. Pitaru S, Tal H, Soldinger M, Noff M. Collagen membranes prevent apical migration of epithelium and support new connective tissue attachment during periodontal wound healing in dogs. J Periodont Res 1989; 24:247-253.

6. Van Swol RL, Ellinger R, Pfeifer J, Barton NE, Blumenthal N. Collagen membrane barrier therapy to guide regeneration in class II furcation in humans. J Periodontol 1993; 64:622-629.

7. Chung KM, Salkin LM, Stein MD, Freedman AL. Clinical evaluation of a biodegradable collagen membrane in guided tissue regeneration. $J$ Periodontol 1990; 61:732-736.

8. Sableman E. Biology, Biotechnology and Biocompatibility of Collagen. Biocompatibility of Tissue Analogs, Vol 1. Boca Raton, Florida: CRC Press, Inc.; 1985; 27.

9. Wikesjö UME, Nilveus RE, Selvig KA. Significance of early healing events on periodontal repair. A review. J Periodontol 1992; 63:158165.

10. Haney JM, Nilveus RE, McMillan PJ, Wikesjö UME. Periodontal repair in dogs: Expanded polytetrafluoroethylene barrier membranes support wound stabilization and enhance bone regeneration. $J$ Periodontol 1993; 64:883-890.

11. Quteisch D, Singrao S, Dolby AE. Light and electron microscopic evaluation of biocompatibility, resorption and penetration characteristics of human collagen graft material. J Clin Periodontol 1991; 18: 305-311.

12. Posthlewaite AE, Seyer JM, Kang AH. Chemostasis attraction of human fibroblast to type I, II and III collagens and collagen derived peptides. Proc Nat Acad Sci (USA) 1978; 75:870-875.
13. Quteisch D, Dolby AE. The use of irradiated-crosslinked human collagen membrane in guided tissue regeneration. $J$ Clin Periodontol $1992 ; 19: 476-484$.

14. Ellender G, Hammond R, Papli R, et al. Osteogenic capacity of collagen in repair of established periodontal defects. Clin Mat 1992; 9: 201-209.

15. Cooperman L, Machaeli D. The immuno-genicity of injectable collagen I. A 1-year prospective study. J Am Acad Dermatol 1984; 10: $638-646$.

16. Greenstein G, Caton JG. Biodegradable barriers and guided tissue regeneration. Periodontology 2000 1993; 1:36-45.

17. Miller SC. Textbook of Periodontia. Philadelphia: The Blakiston Company; 1938:91.

18. Silness J, Löe H. Periodontal disease in pregnancy. II. Correlation between oral hygiene and periodontal condition. Acta Odontol Scand 1964; 22:112-135.

19. Löe H, Silness J. Periodontal disease in pregnancy. I. Prevalence and severity. Acta Odontol Scand 1963; 21:533-551.

20. North American Science Associates, Inc. Laboratory report No. 89T05942-00. Eight week evaluation of a periodontal collagen barrier sponge following subcutaneous implant in the rat

21. Blumenthal NM. A clinical comparison of collagen membranes with ePTFE membranes in the treatment of human mandibular buccal class II furcation defects. $J$ Periodontol 1993; 64:925-933.

22. Paul BF, Mellonig JT, Towle HJ, Gray JL. Use of a collagen barrier to enhance healing in human periodontal furcation defects. Int J Periodontics Restorative Dent 1992; 12:123-131.

23. Anderson $\mathrm{HH}$. The effectiveness of a collagen membrane barrier in achieving new attachment in grade II furcation involvements. [Thesis] Kansas City, Missouri: University of Missouri-Kansas City, 1991.

24. Lekovic V, Kenney EB, Kovacevic K, Carranza FA. Evaluation of guided tissue regeneration in class II furcation defects. A clinical reentry study. J Periodontol 1989; 60:694-698.

25. Caffesse RG, Smith BA, Duff B, et al. Class II furcation treated by guided tissue regeneration in humans: Case reports. $J$ Periodontol 1990; 61:510-514.

26. Hill RW, Ramfjord SP, Morrison EC, et al. Four types of periodontal treatment compared over two years. $J$ Periodontol 1981; 52:655-662.

27. Tempro PJ, Nalbandian J. Colonization of retrieved polytetrafluoroethylene membranes: Morphological and microbiological observation. $J$ Periodontol 1993; 64:162-168.

28. Thomas C, Wang H-L, Syed S. Effect of a resorbable membrane upon subgingival microflora. $J$ Dent Res 1993; 72(Spec. Issue):207(Abstr. 829).

29. Choi SY, Nilveus RE, Minutello RD, Zimmerman GJ, Wikesjö UME. Effect of a collagen matrix on healing in periodontal fenestration defects in dogs. $J$ Periodontol 1993; 64:878-882.

30. Stein MD, Salkin LM, Freedman AL. The effects of guided tissue regeneration membrane placement on healthy periodontal sites. $J$ Periodontol 1993; 64:57-59.

31. Kamer FM, Churukian MM. The clinical use of injectable collagen: A three-year retrospective study. Arch Otolaryngol 1984; 110:93-106.

32. Johns LP, Merritt K, Agarwal S, Ceravolo FJ. Immunogenicity of a bovine collagen membrane in guided tissue regeneration. $J$ Dent Res 1992; 71(Spec. Issue):298(Abstr. 1538).

Send reprint requests to: Dr. Hom-Lay Wang, University of Michigan, School of Dentistry, 1011 N. University Avenue, Ann Arbor, MI 481091078.

Accepted for publication June 4, 1994. 